Check for updates

Cite this: Chem. Sci., 2019, 10, 3118

๑ All publication charges for this article have been paid for by the Royal Society of Chemistry

Received 22nd December 2018

Accepted 23rd January 2019

DOI: $10.1039 / \mathrm{c} 8 \mathrm{sc} 05737 \mathrm{k}$

rsc.li/chemical-science

\section{Pd-catalyzed dearomative arylborylation of indoles $\uparrow$}

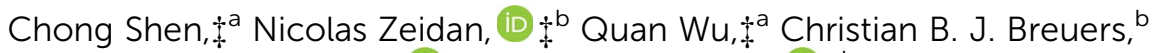 \\ Ren-Rong Liu, ${ }^{a}$ Yi-Xia Jia (D)*ac and Mark Lautens (D) *b
}

A palladium-catalyzed dearomative arylborylation of indoles is reported, which provides straightforward access to structurally diverse indolines bearing vicinal tetrasubstituted and borylated trisubstituted stereocenters in moderate to good yields with excellent diastereoselectivities. By using a BINOL-based chiral phosphoramidite ligand and an $\mathrm{sp}^{2}-\mathrm{sp}^{3}$ mixed-boron reagent, an enantioselective dearomative arylborylation was achieved and chiral boron-containing products were accessed in up to $94 \%$ ee. Synthetic tranformations of the resulting organoborons were conducted to afford a number of unique indoline derivatives.
Boron containing molecules serve as important building blocks due to their capability of participating in carbon-carbon and carbon-heteroatom bond forming reactions and thus are ubiquitous intermediates in the synthesis of various natural products and bioactive compounds. ${ }^{1}$ The palladium-catalyzed 1,2-difunctionalization of olefins involving Heck/anioniccapture sequences has been intensely studied and proceeds via a carbopalladation followed by the capture of the alkyl-Pd species with a variety of nucleophiles. ${ }^{2}$ Domino Heckborylation reactions employing boron reagents as nucleophiles have enabled an efficient method to synthesize $\mathrm{C}_{\mathrm{sp}^{3-}}$ based organoboron compounds (Scheme 1a). ${ }^{3,4}$ It is worthwhile to extend this methodology to the synthesis of structurally diverse, chiral organoboron heterocycles.

The transition-metal-catalyzed dearomative functionalization of aromatics has recently emerged as a useful approach to the synthesis of unique aliphatic cyclic molecules. ${ }^{5}$ In this context, dearomative functionalization of indoles has rendered the synthesis of indolines, a frequently occurring key substructure of natural products and alkaloids, extremely straightforward and efficient. ${ }^{6}$ Documented reports include the intramolecular C3-arylation of an indolic enolate, ${ }^{7}$ the Heck arylation of $\mathrm{N}$-tethered 2,3-disubstituted indoles, ${ }^{8}$ and the

${ }^{a}$ College of Chemical Engineering, State Key Laboratory Breeding Base of Green-Chemical Synthesis Technology, Zhejiang University of Technology, Hangzhou 310014, China. E-mail: yxjia@zjut.edu.cn

${ }^{b}$ Department of Chemistry, University of Toronto, 80 St. George Street, Toronto, Canada.E-mail: mark.lautens@utoronto.ca

'Shanghai Key Laboratory for Molecular Engineering of Chiral Drugs, Shanghai Jiao Tong University, 800 Dongchuan Road, Shanghai 200240, China

$\dagger$ Electronic supplementary information (ESI) available. CCDC 1855293. For ESI and crystallographic data in CIF or other electronic format see DOI: $10.1039 / \mathrm{c} 8 \mathrm{sc} 05737 \mathrm{k}$

\$Contributed equally to this work.
reductive-Heck reaction, ${ }^{9}$ which results in the dearomative mono-functionalization of indole derivatives. Furthermore, the dearomative difunctionalization of indoles was realized through the trapping of the benzyl-Pd intermediate of arylpalladation using a series of trapping agents, such as cyanides,${ }^{10}$ boroxines,${ }^{11}$ terminal alkynes,${ }^{12}$ propiolic acid, ${ }^{13}$ and heteroarenes, ${ }^{14}$ efficiently delivering 2,3 -disubstituted indolines. While the formation of the $\mathrm{C}-\mathrm{H}$ and $\mathrm{C}-\mathrm{C}$ bonds is documented in the aforementioned reports, there are no examples reported for $\mathrm{C}-\mathrm{B}$ bond formation to afford chiral organoboron compounds. We envisioned a dearomative Heck-borylation domino reaction of indole to provide benzylic-boron indolines; the protocol mainly relies on the capture of the in situ generated benzyl-Pd species with diboron compounds. Herein, we report this dearomative arylborylation reaction using bis(pinacolato)diboron $\left(\mathrm{B}_{2} \mathrm{pin}_{2}\right)$, and its enantioselective variant with a pre-activated $\mathrm{sp}^{2}-\mathrm{sp}^{3}$ mixed-boron reagent and a new BINOL-based chiral phosphoramidite ligand, which leads to a series of structurally unique tetracyclic indolines in moderate to good yields, excellent diastereoselectivities, and good to excellent enantioselectivities (Scheme 1b).
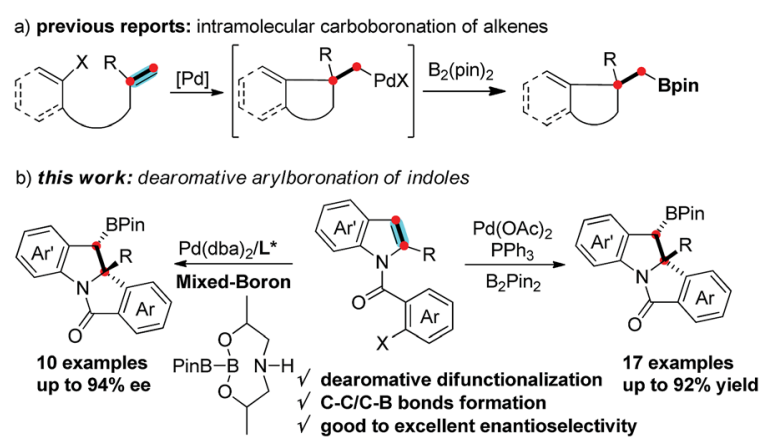

Scheme 1 Palladium-catalyzed arylborylation of $\mathrm{C}=\mathrm{C}$ bonds. 
The reaction of $1 \mathrm{a}$ with $\mathrm{B}_{2} \operatorname{pin}_{2} 2$ was chosen as the starting condition for optimization. An initial test using $\mathrm{Pd}(\mathrm{OAc})_{2}$ (5 mol\%), $\mathrm{PPh}_{3}$ (10 mol\%), and ${ }^{t} \mathrm{BuOLi}$ (2.0 equiv.) in $\mathrm{CH}_{2} \mathrm{Cl}_{2}$ $(0.2 \mathrm{M})$ at $100{ }^{\circ} \mathrm{C}$ led to the desired arylborylation product $3 \mathrm{a}$ in $25 \%$ yield with $>20: 1 \mathrm{dr}$ (Table 1 , entry 1 ). To improve the yield, some bases were screened (entries 2-5). A poor yield was observed when using ${ }^{t} \mathrm{BuOK}$ (Table 1 , entry 2), while $\mathrm{K}_{3} \mathrm{PO}_{4}$, $\mathrm{K}_{2} \mathrm{CO}_{3}$, and $\mathrm{Na}_{2} \mathrm{CO}_{3}$ significantly improve the yield with 3a isolated in $66 \%$ in the case of $\mathrm{K}_{2} \mathrm{CO}_{3}$ (Table 1, entries 3-5). Other commercially available ligands, such as $\mathrm{P}(p \text {-tolyl })_{3}, \mathrm{P}^{t} \mathrm{Bu}_{3}$, and $\mathrm{PCy}_{3}$, were then tested, none of which increased the yield (Table 1, entries 6-8). Moreover, poor yields were also observed for bidentate phosphine ligands, e.g. dppe and xantphos. A lower yield was observed when changing the catalyst from $\mathrm{Pd}(\mathrm{OAc})_{2}$ to $\mathrm{Pd}(\mathrm{dba})_{2}$ (Table 1, entry 9). Higher yields could be obtained by lowering the temperature and 3a was isolated in $83 \%$ yield when the reaction was run at $60{ }^{\circ} \mathrm{C}$ (Table 1, entries 10 and 11). Finally, the solvent effect was examined (Table 1, entries 12-15). Comparable yields were observed in toluene and $\mathrm{CH}_{3} \mathrm{CN}$, while the best yield of $\mathbf{3 a}$ was achieved in DCE solvent (Table 1, entry 15).

With the optimal conditions in hand, we then examined the scope of the reaction by varying the substituents on the halobenzene and indole rings. As shown in Scheme 2, substituent effect on the benzene ring of the 2-bromobenzoyl moiety was first investigated. Moderate to excellent yields of products $\mathbf{3 a}-\mathbf{3 h}$ were achieved for indoles bearing substituents (methyl, methoxyl, and chloride) at the C3-C5 position of the benzene ring. Higher yields were generally obtained for substrates having an electron-donating group than for those bearing an

Table 1 Optimization of the reaction conditions ${ }^{a}$

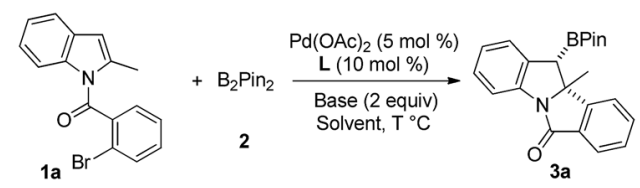

\begin{tabular}{llllll}
\hline Entry & Base & $\mathbf{L}$ & $\mathrm{T}\left({ }^{\circ} \mathrm{C}\right)$ & Solvent & Yield (\%) \\
\hline 1 & ${ }^{t} \mathrm{BuOLi}$ & $\mathrm{PPh}_{3}$ & 100 & $\mathrm{CH}_{2} \mathrm{Cl}_{2}$ & 25 \\
2 & ${ }^{t} \mathrm{BuOK}$ & $\mathrm{PPh}_{3}$ & 100 & $\mathrm{CH}_{2} \mathrm{Cl}_{2}$ & 27 \\
3 & $\mathrm{~K}_{3} \mathrm{PO}_{4}$ & $\mathrm{PPh}_{3}$ & 100 & $\mathrm{CH}_{2} \mathrm{Cl}_{2}$ & 57 \\
4 & $\mathrm{~K}_{2} \mathrm{CO}_{3}$ & $\mathrm{PPh}_{3}$ & 100 & $\mathrm{CH}_{2} \mathrm{Cl}_{2}$ & 66 \\
5 & $\mathrm{Na}_{2} \mathrm{CO}_{3}$ & $\mathrm{PPh}_{3}$ & 100 & $\mathrm{CH}_{2} \mathrm{Cl}_{2}$ & 43 \\
6 & $\mathrm{~K}_{2} \mathrm{CO}_{3}$ & $\mathrm{P} p$-tolyl $)_{3}$ & 100 & $\mathrm{CH}_{2} \mathrm{Cl}_{2}$ & 53 \\
7 & $\mathrm{~K}_{2} \mathrm{CO}_{3}$ & $\mathrm{P}^{t} \mathrm{Bu}_{3} \cdot \mathrm{HBF}_{4}$ & 100 & $\mathrm{CH}_{2} \mathrm{Cl}_{2}$ & 24 \\
8 & $\mathrm{~K}_{2} \mathrm{CO}_{3}$ & $\mathrm{PCy}_{3} \cdot \mathrm{HBF}_{4}$ & 100 & $\mathrm{CH}_{2} \mathrm{Cl}_{2}$ & 17 \\
9 & $\mathrm{~K}_{2} \mathrm{CO}_{3}$ & $\mathrm{PPh}_{3}$ & 100 & $\mathrm{CH}_{2} \mathrm{Cl}_{2}$ & 38 \\
10 & $\mathrm{~K}_{2} \mathrm{CO}_{3}$ & $\mathrm{PPh}_{3}$ & 80 & $\mathrm{CH}_{2} \mathrm{Cl}_{2}$ & 74 \\
11 & $\mathrm{~K}_{2} \mathrm{CO}_{3}$ & $\mathrm{PPh}_{3}$ & 60 & $\mathrm{CH}_{2} \mathrm{Cl}_{2}$ & 83 \\
12 & $\mathrm{~K}_{2} \mathrm{CO}_{3}$ & $\mathrm{PPh}_{3}$ & 60 & $\mathrm{THF}$ & 68 \\
13 & $\mathrm{~K}_{2} \mathrm{CO}_{3}$ & $\mathrm{PPh}_{3}$ & 60 & toluene & 84 \\
14 & $\mathrm{~K}_{2} \mathrm{CO}_{3}$ & $\mathrm{PPh}_{3}$ & 60 & $\mathrm{MeCN}$ & 83 \\
15 & $\mathrm{~K}_{2} \mathrm{CO}_{3}$ & $\mathrm{PPh}_{3}$ & 60 & $\mathrm{DCE}$ & 87
\end{tabular}

${ }^{a}$ Reaction conditions: 1a $(0.2 \mathrm{mmol}), 2$ (2 eq.), $5 \mathrm{~mol} \% \mathrm{Pd}(\mathrm{OAc})_{2}$, $10 \mathrm{~mol} \%$ ligand, and $2 \mathrm{eq}$. base in solvent $(2 \mathrm{~mL})$ at $100{ }^{\circ} \mathrm{C}$; isolated yield, $\mathrm{dr}>20: 1$; DCE $=1$,2-dichloroethane. ${ }^{b} 5 \mathrm{~mol} \% \mathrm{Pd}(\mathrm{dba})_{2}$ was used.

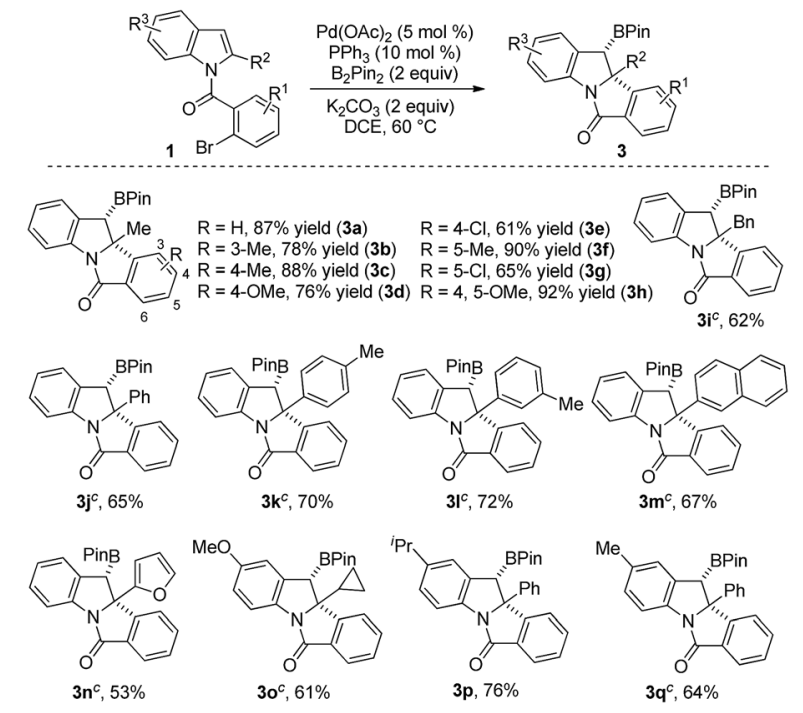

Scheme 2 Scope of the indole substituent. ${ }^{\mathrm{a}}$ Reaction conditions: 1 (0.2 mmol), 2 (2.0 equiv.), $5 \mathrm{~mol} \% \mathrm{Pd}(\mathrm{OAc})_{2}, 10 \mathrm{~mol}^{2} \mathrm{PPh}_{3}$, and $2 \mathrm{eq}$. $\mathrm{K}_{2} \mathrm{CO}_{3}$ in DCE $(2.0 \mathrm{~mL})$ at $60{ }^{\circ} \mathrm{C}$ for $12-72 \mathrm{~h}$. ${ }^{b}$ Isolated yield, $\mathrm{dr}>20: 1$. ${ }^{\mathrm{C}}$ In DCE $(2 \mathrm{~mL})$ at $70{ }^{\circ} \mathrm{C}$ for $18-96 \mathrm{~h}$.

electron-withdrawing substituent (3e and $\mathbf{3 g} v \boldsymbol{v}$. $\mathbf{3 b}-\mathbf{3 d}$ and $\mathbf{3 f}$ ). Product $3 \mathbf{h}$ having two methoxyl groups was isolated in $92 \%$ yield. Of note, $\mathbf{3 b}$, having a sterically congested methyl group at the $\mathrm{C} 3$ position of the bromobenzoyl moiety, was obtained in $78 \%$ yield. Next, the substituent effect on the indole ring was examined. A range of $\mathrm{C} 2$-alkylated and $\mathrm{C} 2$-arylated indoles were subjected to the reaction at $70{ }^{\circ} \mathrm{C}$, which led to the arylborylated products $\mathbf{3} \mathbf{i}-\mathbf{3 n}$ in moderate yields. In contrast, the yields of these borylated indolines were lower than those achieved for 2methyl products $\mathbf{3 a - 3 h}$. It is noteworthy that the reaction of a 2furyl indole substrate successfully delivered $3 \mathbf{n}$ in $53 \%$ yield. Moreover, the substituent at the C5-position of 2-substituted indoles was examined and the reactions of substrates having $\mathrm{MeO}$, iPr, and Me groups afforded 3o-3q in moderate yields.

To demonstrate the synthetic utility of this reaction, a gramscale reaction $(4.0 \mathrm{mmol})$ was carried out under the optimal conditions and afforded $\mathbf{3 a}$ in $77 \%$ yield (Scheme 3 ). Synthetic transformations of $\mathbf{3 a}$ were then conducted. Oxidation of $\mathbf{3 a}$ using $\mathrm{NaBO}_{3} \cdot 4 \mathrm{H}_{2} \mathrm{O}$ in $\mathrm{THF} / \mathrm{H}_{2} \mathrm{O}$ led to alcohol 4 as a single isomer in almost quantitative yield. ${ }^{15}$ Compound $\mathbf{4}$ was further

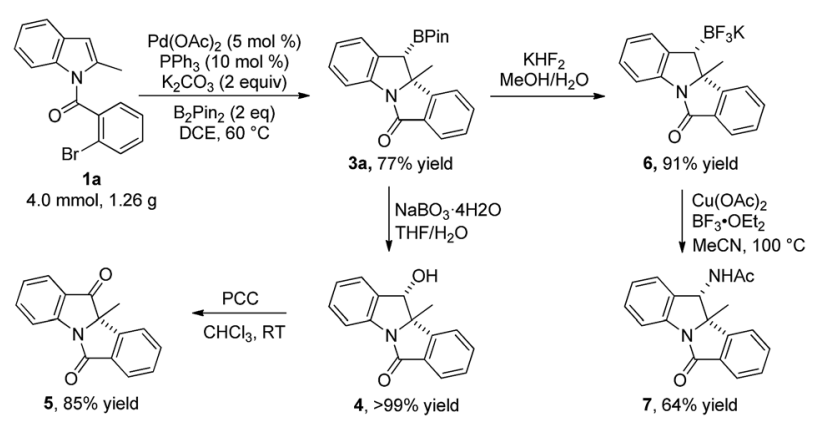

Scheme 3 Gram-scale synthesis of $3 a$ and transformations of $3 a$. PCC: pyridinium chlorochromate. 
oxidized to ketone 5 in $85 \%$ yield with PCC as an oxidant at room temperature. Subjecting $3 \mathbf{a}$ to $\mathrm{KHF}_{2}$ in $\mathrm{THF} / \mathrm{H}_{2} \mathrm{O}$ led to the corresponding potassium trifluoroborate 6 in $91 \%$ yield. Compound 6 was further converted to amide 7 in MeCN with 64\% yield, as a single isomer through a $\mathrm{Cu}(\mathrm{OAc})_{2}$-promoted oxidative nucleophilic substitution. ${ }^{16}$ The relative configurations of alcohol 4 and amide 7 were determined from their 2D-NOESY spectra.

An enantioselective Heck/borylation reaction of 1a was then investigated using phosphoramidite $\mathbf{L 1}$ as the chiral ligand ${ }^{\mathbf{1 2 b}}$ (Table 2, for more details see the ESI $\dagger$ ). Early on, we observed that the benzylic boron was susceptible to inorganic-base promoted proto-deborylation at the high temperatures necessary for this metal-ligand system (vide infra). In order to avoid the use of the inorganic base necessary to activate $\mathrm{B}_{2} \mathrm{Pin}_{2}$, we utilized an $\mathrm{sp}^{2}-\mathrm{sp}^{3}$ mixed boron reagent first reported by Santos for copper-catalyzed hydroboration reactions. ${ }^{17}$ To the best of our knowledge, this reagent has not been used in palladiumcatalyzed borylations. It was necessary to change the solvent from DCE to MTBE since the former was not efficient in the enantioselective variant (Table 2, entry 1 and 2). Although the bromo- and iodo- substrates $\mathbf{1 a}$ and $\mathbf{1 a}^{\prime \prime}$ delivered product in higher yields than the aryl-chloride, it was evident that the smaller halide improved the enantioselectivities (Table 2, entries 2-4). The absolute stereochemistry of 3a was assigned by single-crystal X-ray analysis. ${ }^{18}$

In the case of aryl-chloride, there was no reaction using $\mathrm{B}_{2} \mathrm{Pin}_{2}$ (Table 2, entry 5). We employed an organic base to neutralize the by-product of the boron-reagent and the conversion was improved to $50 \%$ while maintaining the ee (Table 2, entry 6). Further increasing the steric bulk of the ligand improved the yield of the reaction (Table 2, entry 7). Other amines (Table 2, entry 8 ) or lowering the temperature (Table 2, entry 9) were not effective. By increasing ligand and reagent loading the product was delivered in $74 \%$ yield and $94 \%$ ee (Table 2, entry 10 and 11). With respect to the ligand, the nitro variant $\mathbf{L 3}$ was not an effective ligand for the transformation (Table 2, entry 12). The 3,3'-orthoanisole ligand $\mathbf{L 4}$ also did not improve the yield (Table 2, entry 13). The importance of the 3,3' rings was evident as the simple BINOL-derived phosphoramidite $\mathbf{L} 5$ did not produce the product (Table 2, entry 14). Contrary to the dearomative reductive-Heck, ${ }^{9 a}$ BINAP was not effective in catalyzing the reaction (Table 2, entry 15).

Table 2 Optimization of the enantioselecitive arylborylation ${ }^{a}$

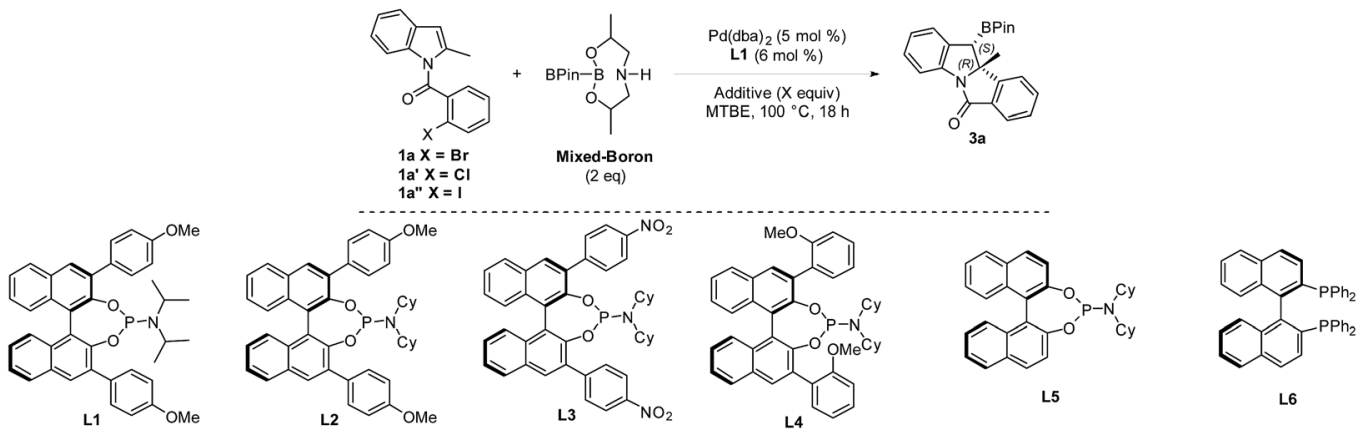

\begin{tabular}{|c|c|c|c|c|c|}
\hline Entry & $\mathrm{x}$ & Additive & Changes to condition & Yield (\%) & ee $(\%$ \\
\hline 1 & $\mathrm{Br}$ & None & None & 73 & 64 \\
\hline 2 & $\mathrm{Br}$ & None & DCE as solvent & 34 & 20 \\
\hline 4 & $\mathrm{Cl}$ & None & None & 15 & 88 \\
\hline 5 & $\mathrm{Cl}$ & $\mathrm{K}_{2} \mathrm{CO}_{3}$ (2 eq.) & $\mathrm{B}_{2} \operatorname{Pin}_{2} \cdot(2$ eq. $)$ & n.r. & - \\
\hline 6 & $\mathrm{Cl}$ & $\mathrm{NEt}_{3}$ (3 eq.) & None & 50 & 88 \\
\hline
\end{tabular}

Entries 8-11 using L2

$\begin{array}{lll}8 & \mathrm{Cl} & { }^{i} \mathrm{Pr}_{2} \mathrm{NEt} \text { (3 eq.) } \\ 9 & \mathrm{Cl} & \left.\mathrm{NEt}_{3} \text { (3 eq. }\right) \\ 10 & \mathrm{Cl} & \left.\mathrm{NEt}_{3} \text { (3 eq. }\right) \\ 11 & \mathrm{Cl} & \left.\mathrm{NEt}_{3} \text { (5 eq. }\right)\end{array}$

Entries 12-15 using conditions in entry 11

$\begin{array}{llllll}12 & \mathrm{Cl} & \mathbf{L 3} & & 17 \\ 13 & \mathrm{Cl} & \mathrm{NEt}_{3} \text { (5 eq.) } & \mathbf{L 4} & 70 & \\ 14 & \mathrm{NEt} & \text { (5 eq.) } & \mathbf{L 5} & \text { Trace } & \\ 15 & \mathrm{Cl} & \mathrm{NEt}_{3} \text { (5 eq.) } & \mathbf{L 6} & - & \text { Trace }\end{array}$

${ }^{a}$ Standard conditions: 1 ( $\left.0.2 \mathrm{mmol}\right)$, mixed-boron reagent (2 eq.), $5 \mathrm{~mol} \% \mathrm{Pd}(\mathrm{dba})_{2}, 6 \mathrm{~mol} \% \mathrm{L1}$, and additive in $\mathrm{MTBE}(2 \mathrm{~mL})$ at $100{ }^{\circ} \mathrm{C}$ for $18 \mathrm{~h}$; isolated yield; ee was determined by chiral HPLC; TMG $=$ tetramethyl guanidine; n.r. $=$ no reaction. 


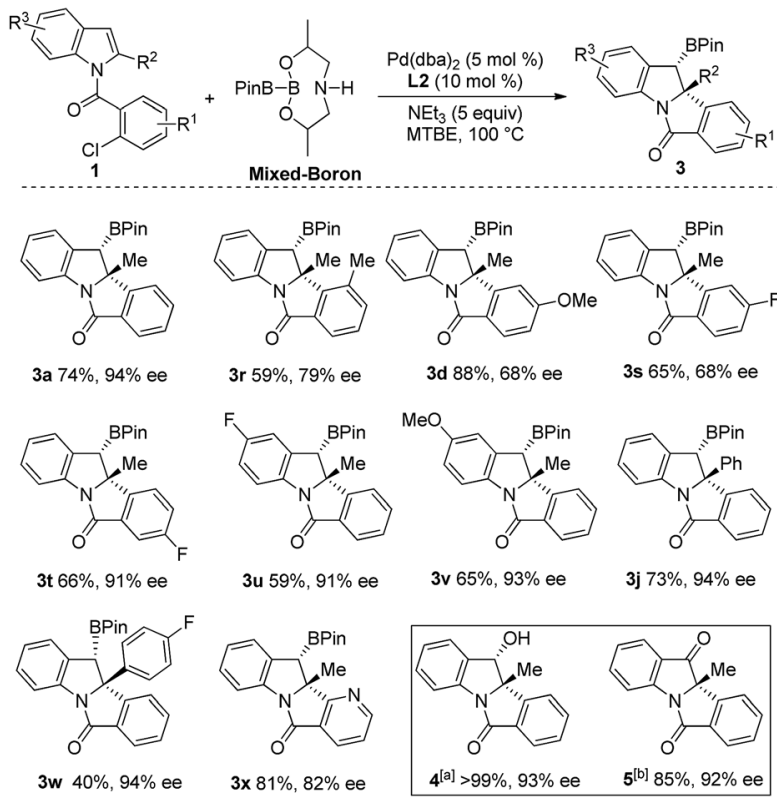

Scheme 4 Scope of Heck/borylation of indoles. Reaction conditions: $1 \mathrm{a}^{\prime}(0.2 \mathrm{mmol})$, (mixed-boron reagent) $(0.6 \mathrm{mmol}), \mathrm{Pd}(\mathrm{dba})_{2}(5 \mathrm{~mol} \%)$, $\mathrm{L} 2(10 \mathrm{~mol} \%), \mathrm{NEt}_{3}\left(5 \mathrm{eq}\right.$.), $100^{\circ} \mathrm{C}, 18 \mathrm{~h}$. [a] Reaction of $4 \mathrm{a}(0.5 \mathrm{mmol})$ with $\mathrm{NaBO}_{3}$ (5 eq.), THF : $\mathrm{H}_{2} \mathrm{O}(1: 1)$, rt. [b] Reaction of $5(0.2 \mathrm{mmol})$ with $\mathrm{PCC}$ (3 eq.), $\mathrm{CHCl}_{3}, 35^{\circ} \mathrm{C}$.

We then examined the scope of the Heck/borylation on various aryl-chloride substrates (Scheme 4). The steric influence at the halide (3r), as well as functionalities para to the amide tether (3d and 3s) provided products in diminished enantioselectivities. In contrast, the substitution para to chloride (3t) or on the indole moiety yielded $\mathbf{3 t}-\mathbf{3 v}$ in moderate yields and excellent enantioselectivities. The aryl functionality at $R^{2}$ resulted in $\mathbf{3 j}$ and $\mathbf{3 w}$ in moderate and good yields with excellent enantioselectivities. Finally, heterocycle containing scaffold $\mathbf{3 x}$ was accessed in good yield albeit in a diminished enantioselectivity. Oxidation of compound 3a provided the chiral alcohol $(+)-4$ and ketone $(+)-5$ with no loss in enantiomeric excess.

\section{Conclusions}

In conclusion, we have developed a dearomative difunctionalization of indoles through a palladium-catalyzed intramolecular arylborylation reaction. Indolines possessing vicinal borylated trisubstituted and tetrasubstituted stereocenters were accessed in good yields and excellent diastereoselectivities. The asymmetric variant of this reaction was explored with a new BINOLbased chiral phosphoramidite ligand and moderate to excellent enantioselectivities were obtained (up to 94\% ee). Transformations of the benzylic boron to alcohol and amide were presented to show the synthetic utilities of this reaction.

\section{Conflicts of interest}

There are no conflicts to declare.

\section{Acknowledgements}

We are grateful for generous support from the National Natural Science Foundation of China (nos. 21522207, 21702184, and 21772175). We thank the Natural Science and Engineering Research Council (NSERC), the University of Toronto, and Alphora Inc. for financial support. N. Z acknowledges the province of Ontario for a Graduate Scholarship (OGS). N. Z. thanks Dr Darcy Burns and the NMR staff at the University of Toronto, as well as Dr Alan Lough for the X-ray results.

\section{References}

1 (a) A. Pelter, K. Smith and H. C. Brown, Borane Reagents, Academic Press, London, 1988; (b) N. Miyaura and A. Suzuki, Chem. Rev., 1995, 95, 2457; (c) M. Davison, A. K. Hughes, T. B. Marder and K. Wade, Contemporary Boron Chemistry; RSC, Cambridge, U.K., 2000; (d) Boronic Acids: Preparation and Applications in Organic Synthesis Medicine and Materials, ed. D. G. Hall, 2nd edn, Wiley-VCH, Weinheim, 2011.

2 For reviews, see (a) R. Grigg and V. Sridharan, J. Organomet. Chem., 1999, 576, 65; (b) G. Poli, G. Giambastiani and A. Heumann, Tetrahedron, 2000, 56, 5959; (c) T. Vlaar, E. Ruijter and R. V. A. Orru, Adv. Synth. Catal., 2011, 353, 809; (d) J. Muzart, Tetrahedron, 2013, 69, 6735; For selected recent examples, see: (e) J. Hu, H. Hirao, Y. Li and J. Zhou, Angew. Chem., Int. Ed., 2013, 52, 8676; (f) X. Wu, H.-C. Lin, M.-L. Li, L.-L. Li, Z.-Y. Han and L.-Z. Gong, J. Am. Chem. Soc., 2015, 137, 13476; (g) W. Kong, Q. Wang and J. Zhu, J. Am. Chem. Soc., 2015, 137, 16028; $(h)$ W. Kong, Q. Wang and J. Zhu, Angew. Chem., Int. Ed., 2016, 55, 9714; (i) S. Tong, A. Limouni, Q. Wang, M.-X. Wang and J. Zhu, Angew. Chem., Int. Ed., 2017, 56, 14192; (j) J. Ye, Z. Shi, T. Sperger, Y. Yasukawa, C. Kingston, F. Schoenebeck and M. Lautens, Nat. Chem., 2017, 9, 361; (k) H. Yoon, M. Rölz, F. Landau and M. Lautens, Angew. Chem., Int. Ed., 2017, 56, 10920; (l) Y. J. Jang, E. M. Larin and M. Lautens, Angew. Chem., Int. Ed., 2017, 56, 11927.

3 (a) H. Yoon, Y. J. Jang and M. Lautens, Synthesis, 2016, 48, 1483; (b) D. D. Vachhani, H. H. Butani, N. Sharma, U. C. Bhoya, A. K. Shah and E. V. Van der Eycken, Chem. Commun., 2015, 51, 14862; F. Wei, L. Wei, L. Zhou, C.-H. Tung, Y. Ma and Z. Xu, Asian J. Org. Chem., 2016, 5, 971; Z. Jiang, L. Hou, C. Ni, J. Chen, D. Wang and X. Tong, Chem. Commun., 2017, 53, 4270.

4 For selected other examples of transition-metal-catalyzed carboborylation of olefins, see: (a) K. B. Smith, K. M. Logan, W. You and M. K. Brown, Chem. - Eur. J., 2014, 20, 12032; (b) K. Semba and Y. Nakao, J. Am. Chem. Soc., 2014, 136, 7567; (c) T. Jia, P. Cao, B. Wang, Y. Lou, X. Yin, M. Wang and J. Liao, J. Am. Chem. Soc., 2015, 137, 13760; (d) K. M. Logan and M. K. Brown, Angew. Chem., Int. Ed., 2017, 56, 851; (e) K. B. Smith and M. K. Brown, J. Am. Chem. Soc., 2017, 139, 7721; (f) S. R. Sardini and M. K. Brown, J. Am. Chem. Soc., 2017, 139, 9823; $(g)$ Y. Huang, K. B. Smith and M. K. Brown, Angew. Chem., Int. 
Ed., 2017, 56, 13314; (h) K. M. Logan, S. R. Sardini, S. D. While and M. K. Brown, J. Am. Chem. Soc., 2018, 140, 159.

5 For reviews, see: (a) A. R. Pape, K. P. Kaliappan and E. P. Kündig, Chem. Rev., 2000, 100, 2917; (b) D.-S. Wang, Q.-A. Chen, S.-M. Lu and Y.-G. Zhou, Chem. Rev., 2012, 112, 2557; (c) C.-X. Zhuo, W. Zhang and S.-L. You, Angew. Chem., Int. Ed., 2012, 51, 12662; (d) C.-X. Zhuo, C. Zheng and S.-L. You, Acc. Chem. Res., 2014, 47, 2558.

6 For reviews, see: (a) S. P. Roche, J.-J. Y. Tendoung and B. Treguier, Tetrahedron, 2015, 71, 3549; (b) J.-B. Chen and Y.-X. Jia, Org. Biomol. Chem., 2017, 15, 3550.

7 K.-J. Wu, L.-X. Dai and S.-L. You, Org. Lett., 2012, 14, 3772.

8 (a) L. Zhao, Z.-Y. Li, L. Chang, J.-Y. Xu, H.-Q. Yao and X.-M. Wu, Org. Lett., 2012, 14, 2066; (b) K. Douki, H. Ono, T. Taniquchi, J. Shimokawa, M. Kitamura and T. Fukuyama, J. Am. Chem. Soc., 2016, 138, 14578; (c) X. Li, B. Zhou, R.-Z. Yang, F.-M. Yang, R.-X. Liang, R.-R. Liu and Y.-X. Jia, J. Am. Chem. Soc., 2018, 140, 13945.

9 (a) C. Shen, R.-R. Liu, R.-J. Fan, Y.-L. Li, T.-F. Xu, J.-R. Gao and Y.-X. Jia, J. Am. Chem. Soc., 2015, 137, 4936; (b) R.-R. Liu, Y. Xu, R.-X. Liang, B. Xiang and Y.-X. Jia, Org. Biomol. Chem., 2017, 15, 2711; (c) R.-X. Liang, R.-Z. Yang, R.-R. Liu and Y.-X. Jia, Org. Chem. Front., 2018, 5, 1840.
10 D. A. Petrone, A. Yen, N. Zeidan and M. Lautens, Org. Lett., 2015, 17, 4838.

11 D. A. Petrone, M. Kondo, N. Zeidan and M. Lautens, Chem. Eur. J., 2016, 22, 5684.

12 (a) R.-R. Liu, T.-F. Xu, Y.-G. Wang, B. Xiang, J.-R. Gao and Y.-X. Jia, Chem. Commun., 2016, 52, 13664; (b) R.-R. Liu, Y.-G. Wang, Y.-L. Li, B.-B. Huang, R.-X. Liang and Y.-X. Jia, Angew. Chem., Int. Ed., 2017, 56, 7475.

13 (a) S. Chen, X.-X. Wu, J. Wang, X.-H. Hao, Y. Xia, Y. Shen, H. Jing and Y.-M. Liang, Org. Lett., 2016, 18, 4016; (b) Y. Wang, R. Liu, J. Gao and Y. Jia, Chin. J. Org. Chem., 2017, 37, 691.

14 N. Zeidan, T. Beisel, R. Ross and M. Lautens, Org. Lett., 2018, 20, 7322 .

15 K. Kubota, K. Hayama, H. Iwamoto and H. Ito, Angew. Chem., Int. Ed., 2015, 54, 8809.

16 C. Cazorla, E. Métay and M. Lemaire, Tetrahedron, 2011, 67, 8615.

17 (a) M. Gao, S. B. Thorpe and W. L. Santos, Org. Lett., 2009, 11, 3478; (b) S. B. Thorpe, X. Guo and W. L. Santos, Chem. Commun., 2011, 47, 424; (c) M. Gao, S. B. Thorpe, C. Kleeberg, C. Slebodnick, T. B. Marder and W. L. Santos, J. Org. Chem., 2011, 76, 3997.

18 CCDC $1855293((+)-3 a)$. 